\title{
Phenotypic characteristics and lipopolysaccharides of human and animal isolates of Fusobacterium necrophorum
}

\author{
R. BROWN, H. G. LOUGH and I. R. POXTON \\ Department of Medical Microbiology, Edinburgh University, Teviot Place, Edinburgh EH8 9AG
}

\begin{abstract}
As part of a collaborative study, six culture collection isolates and 50 coded isolates of Fusobacterium necrophorum were examined for the types of lipopolysaccharides (LPS) they contained, and to see if this related to their reactions in a range of phenotypic tests and their susceptibility to a panel of six antimicrobial compounds. The biotype $B$ type strain, putative biotype $B$ isolates and human isolates were predominantly coccobacillary, had rough type LPS and some of these isolates (8 of 26) required incubation for $>\mathbf{2}$ days to demonstrate lipase activity. The biotype A type strain, putative biotype $\mathrm{AB}$ isolates and most putative biotype $A$ isolates (16 of 18) were predominantly rod-shaped, had either smooth LPS or low $M_{r}$ rough type LPS and all demonstrated lipase activity within 2 days. The other two putative biotype $A$ isolates were coccobacillary and had rough type LPS, and one of these required incubation for $>2$ days to demonstrate lipase activity. The results of these latter two isolates more closely resembled biotype $B$. A few isolates were asaccharolytic, but most fermented one or more of glucose, fructose, maltose and galactose. There was no correlation between fermentation pattern and LPS type, biotype or source of isolate (animal or human) but, with the exception of two abberant isolates, there was good correlation between cellular morphology, type of growth in liquid media and LPS type.
\end{abstract}

\section{Introduction}

The anaerobic gram-negative bacterium Fusobacterium necrophorum is pathogenic for man and animals [1-5]. Previously it had been classified in three distinct species, Sphaerophorus necrophorus, S. funduliforme and $S$. pseudonecrophorus [6] and later as biotypes A, $\mathrm{B}$ and $\mathrm{C}$, respectively, of $F$. necrophorum [7]. Biotype $C$ was reclassified as $F$. pseudonecrophorum on the basis of DNA homology studies, and shown to differ from biotypes $\mathrm{A}$ and $\mathrm{B}$ by its inability to produce lipase, haemolysis and haemagglutination, and was not associated with liver abscess formation in animals [8]. More recently, F. pseudonecrophorum was shown to be the same as $F$. varium and the latter name has been adopted for these strains [9]. Biotypes A and B were reclassified as $F$. necrophorum subsp. necrophorum and F. necrophorum subsp. funduliforme, respectively, on

Received 16 May 1995; accepted 4 Oct. 1995.

Corresponding author: Mr R. Brown.

Publication of this paper was deferred, with the agreement of the authors, to enable simultaneous publication of two other reports $[23,24]$ from the same collaborative study (ed). the basis of DNA homology studies, and shown to differ from each other in tests for haemagglutination, lipase production and mouse lethality [10], and lipopolysaccharides (LPS) extracted from these organisms were shown to differ in their chemical composition and biological properties [11].

There is disagreement between published results for fermentation patterns and lipase activity of these organisms. The aim of this part of a collaborative study of human and animal isolates was to examine the LPS type, to see if this correlated with the phenotypic characteristics and antibiotic susceptibility of isolates of $F$. necrophorum and to compare these results with the stated putative biotypes.

\section{Materials and methods}

\section{Bacterial strains}

F. necrophorum subsp. necrophorum $\mathrm{JCM} 3718^{\mathrm{T}}, F$. necrophorum subsp. funduliforme $\mathrm{JCM} 3724^{\mathrm{T}}$ and $F$. pseudonecrophorum JCM $3722^{\mathrm{T}}$ (F. varium) were obtained from the Japanese Collection of Microorganisms, Wako-shi, Saitama, Japan. F. necrophorum 
NCTC 10575, 10576 and 10577 were obtained from the National Collection of Type Cultures, 61 Colindale Avenue, London. Fifty isolates of $F$. necrophorum (including four duplicate pairs, one pair being duplicates of NCTC 10575) were obtained from Dr J. Brazier, PHLS Anaerobe Reference Unit, Cardiff, as part of a collaborative study; these were received coded F1-F50.

\section{Identification}

Strains were identified by standard phenotypic tests in anaerobe investigation medium (AIM), and gas chromatographic analysis of short-chain fatty-acid endproducts of metabolism by the method of Brown et al. [12]. Cell morphology was examined in cultures grown in AIM-cooked meat broth (CMB). Incubation was at $37^{\circ} \mathrm{C}$ in an anaerobic cabinet (Don Whitley Scientific, Shipley, W. Yorkshire) with an atmosphere of $\mathrm{H}_{2} 10 \%$, $\mathrm{CO}_{2} \quad 10 \%, \mathrm{~N}_{2} 80 \%$.

\section{Extraction of LPS}

This was slightly modified from the method of Fomsgaard et al. [13]. The organisms were grown anaerobically for $22-24 \mathrm{~h}$ in $20 \mathrm{ml}$ of AIM supplemented with glucose $5 \mathrm{~g} / \mathrm{L}$. Cells were harvested by centrifugation at $4000 \mathrm{~g}$ for $20 \mathrm{~min}$ and resuspended in $500 \mu \mathrm{l}$ of pyrogen-free de-ionised water. To the suspended cells, $500 \mu \mathrm{l}$ of phenol $90 \% \mathrm{w} / \mathrm{w}$ aqueous solution were added and, after vortex mixing for $10 \mathrm{~s}$, the suspension was heated at $70^{\circ} \mathrm{C}$ for $10 \mathrm{~min}$. After cooling in an ice bath for at least $2 \mathrm{~min}$ and centrifugation at $3000 \mathrm{~g}$ for $4 \mathrm{~min}$, the clear upper layer was collected and stored at $-20^{\circ} \mathrm{C}$.

\section{Polyacrylamide gel electrophoresis}

LPS extract was mixed with an equal volume of SDSPAGE double strength sample buffer and 25- $\mu \mathrm{l}$ volumes were run on acrylamide $12 \%$ slab gels with the buffer system of Laemmli [14], but excluding SDS. The gels were silver stained by the method of Tsai and Frasch [15], as modified by Hancock and Poxton [16].

\section{Antibiotic susceptibility}

MIC tests were done on Diagnostic Sensitivity Test Agar (Oxoid) supplemented with horse blood $10 \% \mathrm{v} / \mathrm{v}$ and containing two-fold dilutions of antibiotics. The antibiotics tested were metronidazole, co-amoxiclav, imipenem, clindamycin, sparfloxacin and cefoxitin. Plates were inoculated with $c .10^{5} \mathrm{cfu}$ by a multipoint inoculator (Mast Laboratories) and incubated anaerobically for 48 h. MIC range, MIC50 and MIC90 were calculated.

\section{Results}

The coded isolates contained four duplicate pairs, and one of those pairs was the same strain as NCTC 10575. Duplicates within each set gave identical results, except that the authors' isolate of NCTC 10575 failed to lower the $\mathrm{pH}$ of any of the test sugars by $>0.3 \mathrm{pH}$ units below that of the carbohydrate-free control culture, whereas both of the duplicates showed a $\mathrm{pH}$ fall of 0.6 or 0.8 with both glucose and fructose. However, all three isolates were considered to be asaccharolytic. The results obtained with only one isolate of each duplicate (or triplicate) set are included in the following sections.

\section{Identification of isolates}

All isolates were anaerobic, gram-negative, non-motile rods or coccobacilli that produced major amounts of butyric acid and smaller amounts of acetic and propionic acids as end-products of metabolism. Some isolates also produced varying amounts of lactic acid and some produced trace amounts of succinic acid. All isolates converted threonine to propionate and produced indole. With the exception of $F$. pseudonecrophorum JCM 3722, all isolates converted lactate to propionate, did not hydrolyse aesculin, reduce nitrate or digest gelatin, failed to grow or grew poorly in the presence of bile, and produced lipase, although the time taken to detect this effect varied between isolates. $F$. pseudonecrophorum JCM 3722 did not convert lactate to propionate, hydrolysed aesculin, its growth was stimulated in the presence of bile, it did not produce lipase and was the only isolate to ferment mannose. No isolates fermented lactose, sucrose, trehalose or cellobiose, and fermentation of glucose, maltose, fructose and galactose varied between isolates. Isolates could be grouped by a combination of their reactions in converting lactate to propionate and the time taken to detect lipase production (Table 1), or by their fermentation patterns (Table 2).

Table 1. Distribution of culture collection strains and putative biotypes by the ability to convert lactate to propionate and time taken to detect lipase activity

\begin{tabular}{|c|c|c|c|c|c|c|c|c|c|c|}
\hline \multirow[b]{2}{*}{ Pattern } & \multirow{2}{*}{$\begin{array}{l}\text { Lactate to } \\
\text { propionate }\end{array}$} & \multicolumn{2}{|c|}{ Lipase detected by } & \multirow{2}{*}{$\begin{array}{c}\text { Number of } \\
\text { isolates }\end{array}$} & \multicolumn{4}{|c|}{ Putative biotype (n) } & \multirow[b]{2}{*}{ JCM no. } & \multirow[b]{2}{*}{ NCTC no. } \\
\hline & & 2 days & $3-7$ days & & $\mathrm{A}$ & $\mathrm{AB}$ & B & Human & & \\
\hline $\mathrm{a}$ & + & + & $\ldots$ & 41 & 17 & 2 & 3 & 15 & $3718^{*}$ & $10575,10576,10577$ \\
\hline b & + & - & + & 9 & 1 & 0 & 1 & 6 & $3724^{\dagger}$ & $\ldots$ \\
\hline $\mathrm{c}$ & - & - & - & 1 & 0 & 0 & 0 & 0 & $3722^{\ddagger}$ & $\ldots$ \\
\hline
\end{tabular}


Table 2. Distribution of culture collection strains and putative biotypes by their fermentation patterns

\begin{tabular}{|c|c|c|c|c|c|c|c|c|c|c|c|c|}
\hline \multirow[b]{2}{*}{ Pattern } & \multicolumn{5}{|c|}{ Fermentation of } & \multirow{2}{*}{$\begin{array}{c}\text { Number of } \\
\text { isolates }\end{array}$} & \multicolumn{4}{|c|}{ Putative biotype (n) } & \multirow[b]{2}{*}{ JCM no. } & \multirow[b]{2}{*}{ NCTC no. } \\
\hline & glucose & maltose & fructose & galactose & mannose & & A & $\mathrm{AB}$ & B & Human & & \\
\hline 1 & + & + & + & + & - & 11 & 9 & 0 & 2 & 0 & $\ldots$ & $\ldots$ \\
\hline 2 & + & + & + & - & - & 13 & 1 & 0 & 0 & 11 & $\ldots$ & 10576 \\
\hline 3 & + & + & - & + & - & 3 & 2 & 0 & 0 & 1 & $\ldots$ & $\ldots$ \\
\hline 4 & + & - & + & + & - & 3 & 2 & 0 & 1 & 0 & $\ldots$ & $\ldots$ \\
\hline 5 & + & + & - & - & - & 4 & 0 & 0 & 1 & 3 & $\ldots$ & $\ldots$ \\
\hline 6 & + & - & + & - & - & 3 & 1 & 0 & 0 & 0 & $3718^{*}, 3724^{\dagger}$ & $\ldots$ \\
\hline 7 & + & - & - & + & - & 3 & 0 & 2 & 0 & 0 & $\ldots$ & 10577 \\
\hline 8 & + & - & - & - & - & 7 & 2 & 0 & 0 & 5 & $\ldots$ & $\ldots$ \\
\hline 9 & - & - & - & - & - & 3 & 1 & 0 & 0 & 1 & $\ldots$ & 10575 \\
\hline 10 & + & - & + & - & + & 1 & 0 & 0 & 0 & 0 & $3722^{t}$ & $\ldots$ \\
\hline
\end{tabular}

${ }^{*}$ F. necrophorum biotype A

${ }^{\dagger} F$. necrophorum biotype B.

${ }^{\ddagger} F$. pseudonecrophorum (F. varium).

The cellular morphology in liquid culture was either predominantly coccobacillary, with the cells growing in long, meandering chains and in clumps that formed a dense floccular pellet with a virtually clear supernate, or they were predominantly slender rods and filaments that formed an even turbidity throughout the medium with or without some pellet. One isolate (F37) was an exception in that it was predominantly in clumps of filamentous rods after incubation for $24 \mathrm{~h}$, but changed to coccobacilli after $48 \mathrm{~h}$, growth appearing as a dense floccular pellet at both times.

\section{Examination of LPS profiles}

Three types of LPS patterns were demonstrated (Fig. 1). A high $M_{r}$ ladder pattern, typical of smooth LPS, was produced by 11 isolates, including $F$. necrophorum subsp. necrophorum JCM 3718 and $F$. necrophorum NCTC 10577. A rough LPS pattern comprising a large low $\mathrm{M}_{\mathrm{r}}$ mass band was seen in 29 isolates, including $F$. necrophorum subsp. funduliforme JCM 3724 and F. pseudonecrophorum JCM 3722. The remaining 11 isolates, including $F$. necrophorum NCTC 10575 and 10576, produced profiles that comprised only small bands of weakly staining low $M_{r}$ material; similar

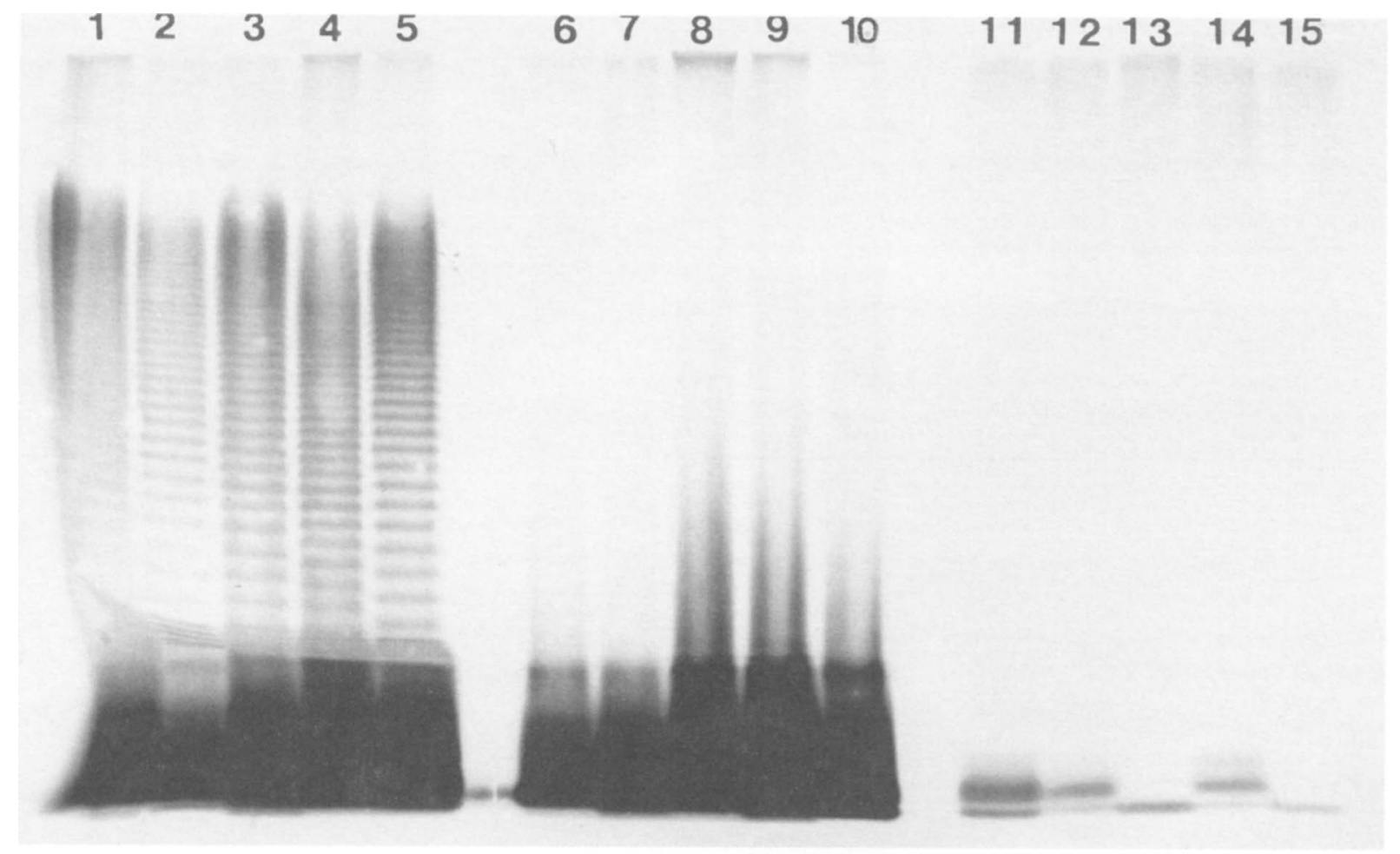

Fig. 1. Silver stain of LPS of $F$ necrophorum. Lanes 1-5, smooth LPS (biotype A and putative biotype A strains JCM 3718, NCTC 10577, F3, F20 and F45); 6-10, rough LPS (biotype B, putative biotype B and human strains JCM 3724 , F1, F4, F19 and F35); 11-15, low $\mathrm{M}_{r}$ LPS (biotype A and putative biotype A and AB strains NCTC 10575, F5, F16, F24 and F46). 
results were obtained from repeated extractions of these isolates even when gels were loaded with increased sample volumes. In some gels a band with a relative mobility of $60 \%$ appears to be common to most of the LPS extracts. However, this band was also found in phenol extracts when sterile culture medium was processed identically to cultures, and probably represents contamination of the extracts. Table 3 shows the distribution of biotypes by LPS type and cell morphology, and Table 4 shows the distribution of each test isolate by group, fermentation pattern, cellular morphology and LPS type. F. pseudonecrophorum was rod-shaped and had a rough type LPS. The other 22 isolates that were predominantly rod-shaped in films from CMB had either smooth LPS patterns or small bands of low $\mathrm{M}_{\mathrm{r}}$ rough types of LPS and comprised $F$. necrophorum subsp. necrophorum JCM 3718, $F$. necrophorum NCTC 10575, 10576 and 10577, 16 putative biotype $\mathrm{A}$ and two putative biotype $\mathrm{AB}$ isolates. All 28 isolates that were predominantly coccoid or coccobacillary in films from $\mathrm{CMB}$ had rough type LPS and comprised $F$. necrophorum subsp. funduliforme JCM 3724, two putative biotype A (F31, F41), four putative biotype B, and 21 human isolates. All nine isolates that required incubation for $>2$ days on egg-yolk agar to show lipase activity (i.e., group b) were coccobacillary and had rough type LPS. This group comprised $F$. necrophorum subsp. funduliforme JCM 3724 , one putative biotype A (F41), one putative biotype $\mathrm{B}$ and six human isolates.

\section{Antibiotic susceptibility}

Table 5 shows the results of MIC tests done on $F$. necrophorum NCTC 10575, 10576 and 10577, $F$. necrophorum subsp. funduliforme JCM 3724, $F$. pseudonecrophorum JCM 3722, 43 other $F$. necrophorum isolates and the control organisms Bacteroides fragilis NCTC 9343 and Clostridium perfringens NCTC 8237. The MIC values for F. pseudonecrophorum JCM 3722 were obviously different from the other isolates; otherwise there was no correlation between susceptibility pattern and fermentation pattern, LPS type or biotype.

Table 3. Distribution of culture collection strains and putative biotypes by cellular morphology and LPS type

\begin{tabular}{|c|c|c|c|c|c|c|c|c|}
\hline \multirow{2}{*}{$\begin{array}{l}\text { Cellular } \\
\text { morphology }\end{array}$} & \multirow[b]{2}{*}{ LPS type } & \multirow{2}{*}{$\begin{array}{c}\text { Number of } \\
\text { Isolates }\end{array}$} & \multicolumn{4}{|c|}{ Putative biotype (n) } & \multirow[b]{2}{*}{ JCM no. } & \multirow[b]{2}{*}{ NCTC no. } \\
\hline & & & A & $\mathrm{AB}$ & $\mathrm{B}$ & Human & & \\
\hline \multirow[t]{3}{*}{ Rods } & Smooth & 11 & 9 & 0 & 0 & 0 & $3718^{*}$ & 10577 \\
\hline & Rough & 1 & 0 & 0 & 0 & 0 & $3722^{*}$ & $\ldots$ \\
\hline & Low $\mathrm{M}_{\mathrm{r}}$ & 11 & 7 & 2 & 0 & 0 & $\ldots$ & 10575,10576 \\
\hline \multirow[t]{3}{*}{ Coccoid } & Smooth & 0 & 0 & 0 & 0 & 0 & $\ldots$ & $\ldots$ \\
\hline & Rough & 28 & 2 & 0 & 4 & 21 & $3724^{\dagger}$ & $\ldots$ \\
\hline & Low $\mathrm{M}_{\mathrm{r}}$ & 0 & 0 & 0 & 0 & 0 & $\ldots$ & $\cdots$ \\
\hline
\end{tabular}

${ }^{*} F$. necrophorum biotype A

${ }^{\dagger} F$. necrophorum biotype B.

${ }^{\ddagger} F$. pseudonecrophorum (F. varium).

Table 4. Distribution of isolates by group, fermentation pattern, cellular morphology and LPS type

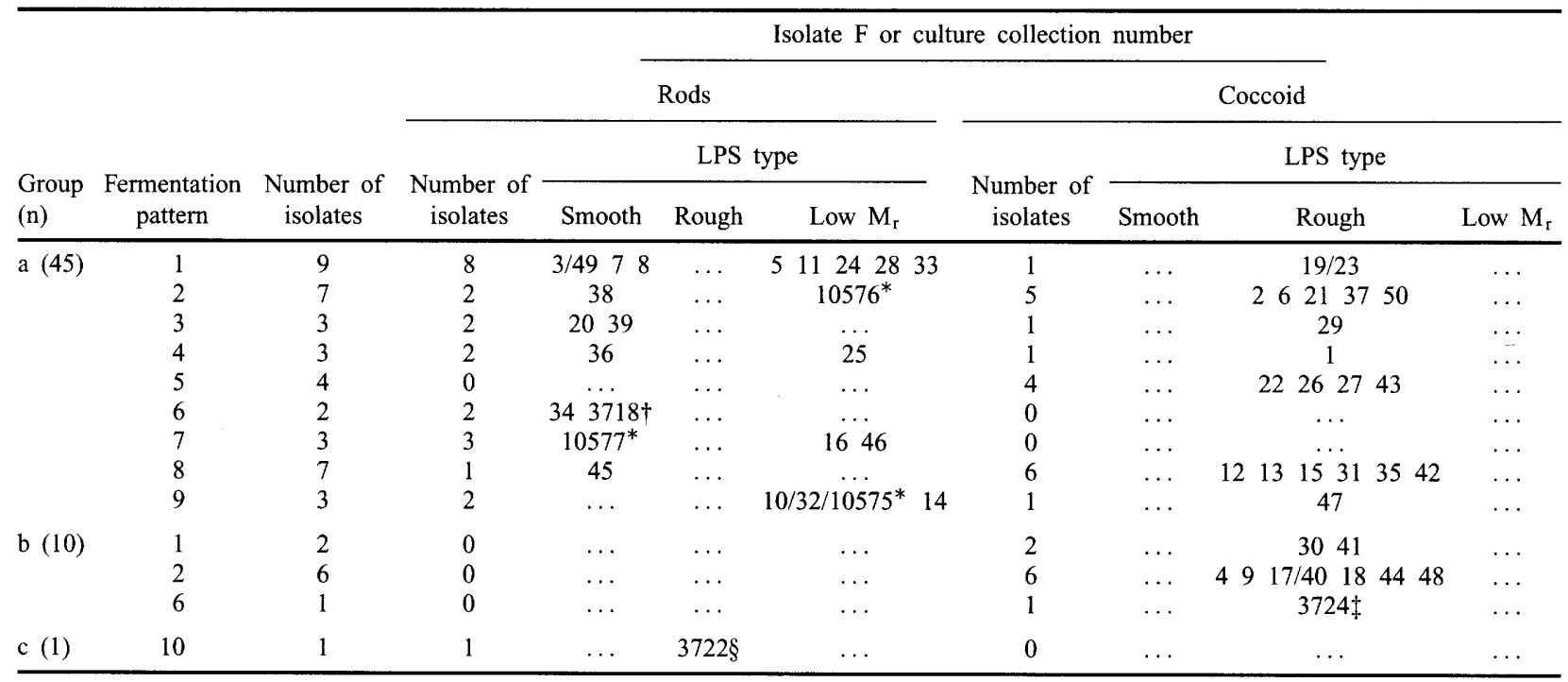

/, Duplicates of the same strain, and counted as one isolate in the 'Number of isolates' columns.

* $F$. necrophorum NCTC isolates.

$\dagger F$. necrophorum biotype $\mathrm{A}, \mathrm{JCM}$ isolate.

$\ddagger F$ necrophorum biotype $\mathrm{B}, \mathrm{JCM}$ isolate.

$\S F$. pseudonecrophorum ( $F$. varium), JCM isolate. 
Table 5. MIC range, MIC50 and MIC90 of $47 F$ necrophorum isolates to six antimicrobial compounds

\begin{tabular}{lcccccccc}
\hline & & \multicolumn{5}{c}{ MIC $(\mathrm{mg} / \mathrm{L})$ of } \\
\cline { 3 - 8 } Species & Strain no. & & co-amoxiclav & cefoxitin & clindamycin & imipenem & metronidazole & sparfloxacin \\
\hline F. necrophorum & (47 isolates) & Range & $\leqslant 0.01-0.25$ & $\leqslant 0.06-0.25$ & $0.06-0.25$ & $\leqslant 0.008-0.06$ & $0.06-0.5$ & $0.25-4$ \\
& & MIC50 & 0.06 & $\leqslant 0.06$ & 0.12 & 0.01 & 0.12 & 2 \\
F. pseudonecrophorum & JCM 3722 & MIC90 & 0.12 & 0.12 & 0.12 & 0.03 & 0.25 & 2 \\
B. fragilis & NCTC 9343 & 2 & 16 & 0.5 & 8 & 0.25 & 8 \\
C. perfringens & NCTC 8237 & & $\leqslant 0.06$ & $\leqslant 0.5$ & 0.06 & 0.25 & 0.5 & 1 \\
\hline
\end{tabular}

\section{Discussion}

The results obtained here are in agreement with others [9] that $F$. pseudonecrophorum is a synonym for $F$. varium. $F$. necrophorum subsp. necrophorum (F. necrophorum biotype A) and $F$ necrophorum subsp. funduliforme ( $F$. necrophorum biotype $\mathrm{B}$ ) have been differentiated by various workers by colonial morphology [17-19], cell morphology [17-19], haemagglutination patterns [7, 17-19], lipase activity [8-10, 19], haemolysis [7, 17-19], and mouse lethality [18, 19]. There is good agreement in the published results for most of these tests, but lipase activity of biotype B has been reported as both positive $[8,9]$ and negative $[10$, 19]. In this study, excepting $F$. pseudonecrophorum, all isolates gave positive results for lipase activity although the biotype $\mathrm{B}$ type strain, one putative biotype B isolate, six human isolates and one putative biotype A isolate (F41) required incubation for $\geqslant 3$ days to detect this. However, isolate F41 produced coccobacillary cells and a rough type LPS and more closely resembles biotype $\mathrm{B}$ than biotype $\mathrm{A}$.

The fermentation of glucose, fructose, maltose, mannose and galactose has variably been reported for $F$. necrophorum. Conflicting reports on fermentation results probably arose because different methods were used to measure fermentation. Some researchers [20] interpret fermentation as being positive when the final $\mathrm{pH}$ value is below 5.5, weak between 5.5 and 6.0 and negative above that level, and report most strains of $F$. necrophorum as asaccharolytic but with some strains giving weak results with glucose and fructose. Another study [17] found the terminal $\mathrm{pH}$ range from glucose fermentation to be 5.35-6.1 and, in tests with bromothymol blue which would indicate acid at $\mathrm{pH}$ 6.0 and below, reported the majority of $F$. necrophorum isolates to ferment glucose, fructose, maltose, mannose and galactose after incubation for 4 days. In this study, fermentation was considered positive if the $\mathrm{pH}$ of the test carbohydrate culture was $1 \mathrm{pH}$ unit or more below that of a carbohydrate-free culture (i.e., at least 10 times more acidic than control). After incubation for 2 days, the glucose fermentation $\mathrm{pH}$ ranged from 5.4 to 7.2 (average 5.79 ), with the $\mathrm{pH}$ of the majority (48 of 51) of isolates being from 5.55 to 5.85. Only three isolates - NCTC 10575 , one putative biotype $\mathrm{A}(\mathrm{F} 14)$ and one human isolate (F47) - failed to ferment any of the test carbohydrates. Other isolates of $F$. necrophorum fermented one or more of glucose, fructose, maltose and galactose, and only the $F$. pseudonecrophorum strain fermented mannose. There was no relationship between fermentation pattern and either animal biotype or human source, or LPS type.

In films from CMB cultures the cellular morphology was predominantly either coccobacillary or rods and filaments. All of the isolates that were coccobacillary had rough type LPS, and included the biotype B type strain, all four putative biotype B isolates, all 21 human isolates and two putative biotype A (F31, F41) isolates. These latter two isolates need to be tested for virulence and haemagglutination in order to re-assess their designation of biotype A.

Isolates that were rods and filaments demonstrated two distinct types of LPS: 1, a ladder pattern typical of smooth LPS, and included $F$. necrophorum JCM $3718^{\mathrm{T}}$, NCTC 10577 and nine putative biotype A isolates; 2, an LPS pattern that comprised only small amounts of low $\mathrm{M}_{\mathrm{r}}$ material, and included F. necrophorum NCTC 10575, NCTC 10576, seven putative biotype $\mathrm{A}$ and two putative biotype $\mathrm{AB}$ isolates. This latter LPS pattern was also demonstrated in repeated extractions, even when the amount of sample run in gels was increased, suggesting a weak staining reaction with silver by its resistance to oxidation by periodate. With the exception of the two putative biotype $\mathrm{A}$ isolates (F31, F41) that were coccobacillary and had rough type LPS, there was good correlation between cellular morphology, biotype or species source, and LPS type.

Intraperitoneal inoculation of viable cells of $F$. necrophorum into mice showed biotype $\mathrm{A}$ isolates to be more lethal than those of biotypes $\mathrm{B}$ and $\mathrm{AB}$. However, LPS extracted from the same strains showed only minor differences in endotoxicity between biotypes $\mathrm{A}$ and $\mathrm{B}$ when tested similarly in mice, whereas biotype $\mathrm{AB}$ was much less endotoxic [21]. In contrast, the LPS of $F$. necrophorum biotype A (VPI 2891, the parent strain of JCM $3718^{\mathrm{T}}$ ) has been shown to differ in its chemical composition and biological activity from that of biotype B [11]. The latter authors employed chick embryo lethality, local Shwartzman reaction and febrile responses in rabbits to demonstrate these differences, tests that are probably more sensitive than mouse lethality for detecting endotoxins. 
In the present study, with the exception of isolates F31 and F41, the type strain and 10 putative biotype A isolates had smooth type LPS, whereas nine other putative biotype $\mathrm{A}$ and two putative biotype $\mathrm{AB}$ isolates had LPS comprising small amounts of low $M_{r}$ material only. Biotyping of $F$. necrophorum is based on the results of tests for cellular morphology, sedimentation in broth culture, colonial morphology, direct haemagglutination, and virulence and pathogenicity [7, 17, 21]. Only the first two of these tests were done by the authors and, in the results obtained, the putative biotype $\mathrm{AB}$ isolates resembled biotype $\mathrm{A}$. However, results of other tests done by our collaborators might show that the isolates with a low $M_{r}$ rough type LPS form a cluster distinct from the type strain of biotype A.

It has been shown, with the exception of one aberrant strain (not included in this study), that human isolates resemble those of biotype $\mathrm{B}$ in being of low pathogenicity in mice [22]. In this study, the type strain (JCM 3724), all four putative biotype B and all 21 human isolates had a rough type LPS. This indicates that there may be a relationship between LPS type and virulence in isolates of $F$. necrophorum.

\section{References}

1. Simon PC, Stovell PL. Diseases of animals associated with Sphaerophorus necrophorus: characteristics of the organism. Vet Bull (London) 1969; 39: 311-315.

2. Smith LDS (ed). The pathogenic anaerobic bacteria, 2nd edn. Springfield, IL, Thomas. 1975.

3. Wilson GS, Miles AA (eds). Topley and Wilsons Principles of bacteriology, virology and immunity, 6th edn. Baltimore, Williams and Wilkins Co. 1975.

4. Barnes EM, Goldberg HS. The relationship of bacteria within the family Bacteroidaceae as shown by numeric taxonomy. $J$ Gen Microbiol 1968; 51: 313-324.

5. Langworth BF. Fusobacterium necrophorum: its characteristics and role as an animal pathogen. Bacteriol Rev 1977; 41: $373-$ 390.

6. Prevot AR (ed). Manuel de classification et de détermination des bactéries anaerobes, 1st edn. Paris, Masson and Co. 1940.

7. Fievez L (ed). Étude comparée des souches de Sphaerophorus necrophorus isolées chez l'homme et chez l'animals. Brussels, Presses Academique Européennes. 1963.

8. Shinjo T, Hiraiwa K, Miyazato S. Recognition of biovar C of Fusobacterium necrophorum (Flugge) Moore and Holdeman as Fusobacterium pseudonecrophorum sp. nov., nom. rev. (ex Prevot 1940). Int J Syst Bacteriol 1990; 40: 71-73.
9. Bailey GD, Love DN. Fusobacterium pseudonecrophorum is a. synonym for Fusobacterium varium. Int J Syst Bacteriol 1993; 43: $819-821$

10. Shinjo T, Fujisawa T, Mitsuoka T. Proposal of two subspecies of Fusobacterium necrophorum (Flugge) Moore and Holdeman: Fusobacterium necrophorum subsp. necrophorum subsp. nov., nom. rev. (ex Flugge 1886), and Fusobacterium necrophorum subsp. funduliforme subsp. nov., nom. rev. (ex Halle 1898). Int J Syst Bacteriol 1991; 41: 395-397.

11. Inoue $T$, Kanoe $M$, Goto $N$, Matsumura $K$, Nakano $K$ Chemical and biological properties of lipopolysaccharides from Fusobacterium necrophorum biovar A and biovar B strains. Jpn J Vet Sci 1985; 47: 639-645.

12. Brown R, Collee JG, Poxton IR. Bacteroides, Fusobacterium and other Gram-negative anaerobic rods: anaerobic cocci: identification of anaerobes. In: Collee JG, Duguid JP, Fraser AG, Marmion BP (eds) Mackie and MacCartney's Practical medical microbiology, 14th edn. London, Churchill Livingstone. 1996: 501-519.

13. Fomsgaard A, Shand GH, Freudenberg MA et al. Antibodies from chronically infected cystic fibrosis patients react with lipopolysaccharides extracted by new micromethods from all serotypes of Pseudomonas aeruginosa. APMIS 1993; 101: $101-112$.

14. Laemmli UK. Cleavage of structural proteins during the assembly of the head of bacteriophage T4. Nature 1970; 227: $680-685$.

15. Tsai C-M, Frasch CE. A sensitive silver stain for detecting lipopolysaccharides in polyacrylamide gels. Anal Biochem 1982; 119: 115-119.

16. Hancock IC, Poxton IR. Bacterial cell surface techniques. Chichester, John Wiley. 1988.

17. Aalbeak B. Sphaerophorus necrophorus. A study of 23 strains. Acta Vet Scand 1971; 12: 344-364.

18. Shinjo T, Miyazato S, Kaneuchi C, Mitsuoka T. Physical and biochemical characteristics of Fusobacterium necrophorum biovar A and biovar B strains and their deoxyribonucleic acid homology. Jpn J Vet Sci 1981; 43: 233-241.

19. Nicholson LA, Morrow CJ, Corner LA, Hodgson ALM Phylogenetic relationship of Fusobacterium necrophorum A, $\mathrm{AB}$ and $\mathrm{B}$ biotypes based upon 16S rRNA gene sequence analysis. Int $J$ Syst Bacteriol 1994; 44: 315-319.

20. Holdeman LV, Cato EP, Moore WEC (eds). Anaerobe laboratory manual, 4th edn. Blacksburg, Virginia Polytechnic Institute. 1977.

21. Berg JN, Scanlan CM. Studies of Fusobacterium necrophorum from bovine hepatic abscesses: biopsies, quantitation, virulence and antibiotic susceptibility. Am J Vet Res 1982; 43: 15801586.

22. Smith GR, Thornton EA. Pathogenicity of Fusobacterium necrophorum strains from man and animals. Epidemiol Infect 1993; 110: 499-506.

23. Hall V, Duerden BI, Magee JT, Ryley HC, Brazier JS. A comparative study of Fusobacterium necrophorum strains from animal and human sources by phenotypic reactions, pyrolysis mass spectrometry and SDS-PAGE. J Med Microbiol 1997; 46: $865-871$.

24. Smith GR, Thornton EA. Classification of human and animal strains of Fusobacterium necrophorum by their pathogenic effects in mice. $J$ Med Microbiol 1997; 46: 879-882. 